\title{
Aging of the hematopoietic stem cells niche
}

\author{
Ayako Nakamura-Ishizu $\cdot$ Toshio Suda
}

Received: 1 July 2014/Revised: 10 July 2014/ Accepted: 11 July 2014/Published online: 6 August 2014

(C) The Japanese Society of Hematology 2014

\begin{abstract}
Homeostasis of the hematopoietic system has its roots in the maintenance of hematopoietic stem cells (HSCs) in the bone marrow (BM). HSCs change both phenotypically and functionally with physiological age. The alterations noted in aged HSCs are thought to be a consequence of both cell-intrinsic and extrinsic changes. We review here the age-related changes that the $\mathrm{BM}$ microenvironment exerts on HSCs.
\end{abstract}

Keywords Aging $\cdot$ Hematopoietic stem cells $\cdot$ Niche . Bone marrow

\section{Introduction}

Hematopoietic stem cells (HSCs) reside at the apex of the hierarchy of hematopoietic cells [1]. HSCs are defined by their multi-lineage differentiation potential and self-renewal capacity, both of which are critical for adequate replenishment of mature hematopoietic cells [2]. HSC stem cell potential alters with age: aged HSCs exhibit skewing to myeloid lineages [3], loss of homing potential [4, 5], and lower repopulation potential upon bone marrow (BM) transplantation [4, 6] (Fig. 1). Studies have focused on cell autonomous processes as the leading cause of age-related cellular changes, but cell extrinsic influences on HSCs are undeniable, during both physiological homeostasis and stress hematopoiesis. The

\footnotetext{
A. Nakamura-Ishizu $(\bowtie) \cdot$ T. Suda $(\square)$

Department of Cell Differentiation, The Sakaguchi Laboratory,

Keio University, 35 Shinano-machi, Shinjuku-ku,

Tokyo 160-8582, Japan

e-mail: ayaknakm@a3.keio.jp

T. Suda

e-mail: sudato@z3.keio.jp
}

elucidation of extrinsic factors that affect HSC aging is crucial for a complete understanding of the niche changes during aging. We review here the recent advances in niche regulation of HSCs in relation to HSC aging and highlight new insights into age-related changes in the BM niche.

\section{The HSC niche}

The adult BM forms a specialized microenvironment (i.e., a niche), which regulates the quiescence, self-renewal, proliferation, and differentiation of HSCs [7]. Research on the HSC niche initially focused on niche functions of nonhematopoietic cells within the BM. The currently identified niche cells that are non-hematopoietic in origin include immature osteoblasts $[8,9]$, endothelial cells $[10,11]$, perivascular cells $[10,12]$, mesenchymal stem cells (MSC) [13], sympathetic nerve cells [14], adipocytes [15], and non-myelinating Schwann cells [16]. Nonetheless, mature hematopoietic cells such as macrophages/monocytes [17] and regulatory T-cells [18], as well as osteoclasts [19], also regulate HSCs or progenitor cells, primarily in an indirect manner through modulation of non-hematopoietic niche cells. Collectively, niche cells regulate HSCs through the production of an array of cytokines, such as angiopoietin-1 (Ang-1), CXCL12, and thrombopoietin (TPO), and extracellular matrix proteins, such as osteopontin and tenascin$\mathrm{C}$, as well as adhesion molecules such as N-cadherin [10, 12, 20-24] (Fig. 2).

Due to the identification of a plethora of cells constituting the niche, the function of the niche has only been depicted as the sum of the effect of niche factors produced and secreted by various niche cells. However, recently, utilization of genetic models in which specific molecules are deleted in specific cells has provided further clarification of niche function undertaken by a specific niche cell. 


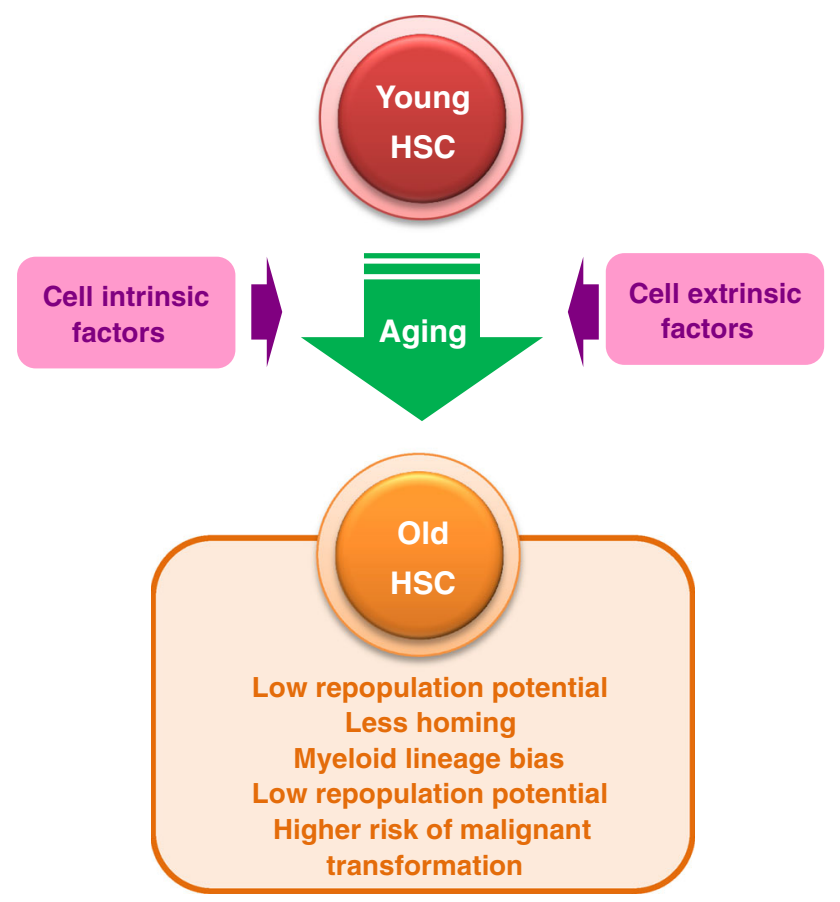

Fig. 1 Characteristics of aged HSCs. Both cell-intrinsic and -extrinsic factors affect aging of HSCs

These studies used mice in which Cre recombinase is expressed under a cell-specific reporter to delete specific niche factors (Table 1). The critical function of stem cell factor (SCF) on HSC maintenance was elucidated through the analysis of $S l / S l^{d}$ mutant mice [45], but the cellular origin of SCF was only recently clarified through cellspecific deletion of SCF from various cells using hematopoietic cell (Vavl-Cre), osteoblast (Col2.3-Cre), Nestin ${ }^{+}$ perivascular cell (Nestin-Cre), endothelial cell (Tie2-Cre), and perivascular cell (Lepr-Cre) Cre mice [10]. This study revealed that the SCF production required for HSC maintenance was predominantly found in endothelial cells and perivascular cells. Similar studies investigated the cellular source of the chemokine CXCL-12 [chemokine (C-X-C motif) ligand 12], which is a known regulator of HSCs and lymphoid progenitors [46, 47]. The two independent reports using cell-specific depletion models of CXCL-12 both identified endothelial cells and perivascular stromal cells as the cells affecting HSC stem cell potential [48, 49]. Interestingly, depletion of $\mathrm{Cxcl12}$ from osteoblasts (Col2.3$\mathrm{Cre}$ ) or osterix-positive stromal cells only resulted in changes in cells committed to the lymphoid lineage [48, 49]. These results demonstrate a correlation between specific niche cells and niche functions and broaden our understanding of the HSC niche: niche cells form specific functional compartments for HSC regulation.

The aging microenvironment in stem cell systems

Before reviewing age-related changes in the HSC niche, it is crucial to note the elegant studies that document the influence of aging in stem cell niches other than the hematopoietic system. In these studies, aging of the niche affects stem cells directly through adhesion to, or secretion of, signaling molecules, or indirectly through systemic circulating factors. In the Drosophila ovary, ovarian germline stem cells (GSCs) reside in a niche formed by cap cells [50]. A decline in Bone morphogenic protein (BMP) signaling through the removal of the $g b b$ and $d b b$ genes in cap cells accelerates ovarian GSC aging [51]. Additionally, E-cadherin-mediated adhesion of GSCs to cap cells decreases with age, and overexpression of E-cadherin can prolong GSC life span [51]. Similarly, Drosophila testicular GSC aging depends on alterations in niche signaling [52]. Testicular GSCs rely on signals from their niche, termed the germ cell hub [53]. An age-associated decline of IGF-II messenger RNA binding protein (IMP) that stabilizes the self-renewal signal Unpaired $(U p d)$ on hub cells
Fig. 2 Components of the HSC niche. Various bone marrow niche cells produce extracellular matrix (ECM) molecules, adhesion molecules and cytokines to maintain HSCs
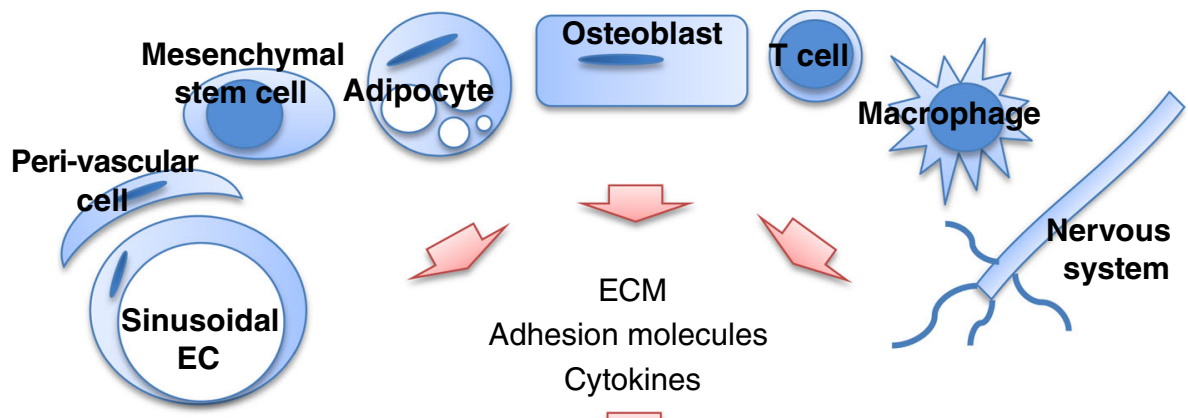

Adhesion molecules Cytokines

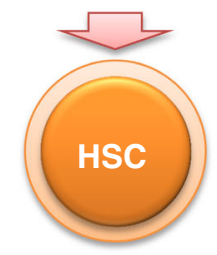


Table 1 Summary of various Cre recombinase-expressing transgenic mice used to investigate niche cell function

\begin{tabular}{|c|c|c|c|}
\hline Cell type & Transgenic mice & Inducible & References \\
\hline \multirow[t]{5}{*}{ Endothelial cell } & Tie2-Cre & No & {$[25,26]$} \\
\hline & VE-cadherin-Cre & No & {$[27]$} \\
\hline & $V E$-cadherin-CreER $R^{T}$ & Yes (Tamoxifen) & {$[28]$} \\
\hline & VE-Cadherin:tTA-Cre & Yes (Tetracyclin) & [29] \\
\hline & $C d h 5(P A C)-C r e E R^{T 2}$ & Yes (Tamoxifen) & {$[30]$} \\
\hline \multirow[t]{3}{*}{ Stromal cell } & Prx-Cre & No & {$[31]$} \\
\hline & Nestin-Cre & No & {$[32]$} \\
\hline & Lepr-Cre & No & [10] \\
\hline \multirow[t]{4}{*}{ Osteoblast } & Ocn-Cre & No & {$[33]$} \\
\hline & Col2.3-Cre & No & {$[34,35]$} \\
\hline & Osxl-Cre & No & {$[36]$} \\
\hline & Osxl-CreER ${ }^{T 2}$ & Yes (Tamoxifen) & [37] \\
\hline Osteocyte & Dmpl-Cre & No & {$[38,39]$} \\
\hline \multirow[t]{4}{*}{ Hematopoietic cell } & Tie2-Cre & No & {$[25,26]$} \\
\hline & Mx-1-Cre & Yes (pIpC) & {$[40]$} \\
\hline & Vav-1-Cre & No & [41-43] \\
\hline & Scl-Cre-ER ${ }^{T}$ & Yes (Tamoxifen) & {$[44]$} \\
\hline
\end{tabular}

affects GSC aging [52, 54]. Furthermore, older males express less DE-cadherin which reduces adhesion of GSCs to hub cells leading to age-related loss of GSCs [55].

Age-related changes in direct and indirect niche signaling have also been implicated in mammalian stem cells. In the adult mouse brain, neurogenesis persists in the subventricular zone of the lateral ventricles and the hippocampus through the differentiation and expansion of neural stem cells [56]. The integrity of neural stem and progenitor cells is supported primarily by endothelial cells in the niche [57]. Neural stem and progenitor cells within these niche regions decrease in number and self-renewal potential with age [58, 59]. An age-related decline in mouse brain neurogenesis depends upon the influence of niche cell production of TGF- $\beta$ on neural stem cells [60]. In the muscles of aged mice, satellite cells that serve as stem cells to replenish injured myocytes show lower activation potentials due to decreased production of the Notch ligand Delta [61], and overproduction of TGF- $\beta$ [62] within the microenvironment.

Studies from heterochronic parabiotic mice, in which the circulatory system of aged mice are surgically connected to that of young mice, have also revealed qualitative differences between aged and young systemic environments [63]. Heterochronic parabiosis enhanced the responses of aged mice to muscular injury [64]. The satellite cell activation for the rejuvenation of muscles in aged mice was promoted by stimulation of Notch signaling, which was presumably mediated by factors in the serum of the young mice [61, 64]. By contrast, the aged systemic microenvironment inhibits satellite cell functions [65].
Aged liver rejuvenation through the expansion of hepatocytes was also positively affected through parabiosis [64]. By contrast, neurogenesis in young mice was inhibited by blood-borne chemokines, including CCL-11, produced by aged mice in heterochronic parabiosis [66]. Furthermore, remyelination through differentiation of oligodendrocyte precursor cells into oligodendrocytes improved in aged mice through the action of circulating monocytes produced by the young mice during parabiosis [67]. However, as parabiosis surgically connects two mice, the invasive procedure may cause changes in systemic inflammatory cytokines, making the analysis of these mice difficult. In summary, age-related changes in both systemic and local environments affect stem cell properties.

\section{Age-related changes in BM niche cells}

The BM microenvironment changes substantially with age. Differences in the cellular composition of the aged and young HSC niche pose questions for the relevance of the niche during aging of the hematopoietic system [68]. Extensive studies have shown that MSCs serve as a niche regulating HSC integrity [13]. An age-related decline in the fraction of $\mathrm{CD} 90+, \mathrm{CD} 105+\mathrm{MSCs}$ has been noted in rats [69], yet consensus has not been reached as to whether high purity MSC fractions change niche functions with age in mice and humans [70]. Nevertheless, the proliferative capacity of human MSCs was shown to decline with age [71]. Clarification of age-related MSC changes will require more stringent identification and characterization of purified MSCs along with precise functional assays. 
Another feature of the aged BM is the prominent increase in adipocytes [15]. Increases in adipocytes in the $\mathrm{BM}$ are associated with lower HSC stem cell potential. Lipoatrophic A-ZIP/F1 mice, which are genetically incapable of adipocyte formation, show an increase in HSC engraftment after irradiation [15]. Although the increase in fat content in the BM with age suggests a change in lipid metabolism, it is not yet known whether aged adipocyte tissue causes the change in metabolic function. Nevertheless, studies have revealed that impaired lipid metabolism in the microenvironment affects HSC function. Cholesterol efflux regulators such as the adenosine triphosphate-binding cassette $(\mathrm{ABC})$ transporters $\mathrm{ABCA} 1$ and $\mathrm{ABCG} 1$, and high-density lipoprotein (HDL) levels inhibit hematopoietic stem and progenitor cells' (HSPC) proliferation, linking HSC function to cholesterol metabolism [72]. Recently, the function of the transcription factor, Forkhead box $\mathrm{c} 1$ (Foxc1) was demonstrated to inhibit adipogenic processes in mice [73]. Conditional deletion of Foxcl in mesenchymal cells, using Prx-1-Cre or Lepr-Cre mice, resulted in replacement of BM cells with adipocytes and a loss of BM HSCs. Although the adipogenic change was not noted in induced deletion of Foxcl in adult mice using $U b c$ $\mathrm{CreER}^{T 2}$ mice, the study revealed a critical role for Foxc1 in adipogenesis in the BM, which may be related to the increase in BM adipocytes with age. A precise characterization of the aging niche is still needed along with a deeper understanding of the functional significance that the niche conveys on aged HSCs.

HSC regulation by aged niche cells

The question remains as to whether aged BM niche cells induce age-related changes in HSCs. Aged HSCs demonstrate a lower engraftment upon BM transplantation [6] and evidence suggests that aging in the microenvironment influences HSC engraftment. Hematopoietic cells engrafted in subcutaneous implantation of BM stroma from both aged and young mice exhibit lower spleen colony-forming units (CFU-S) in hematopoietic cells seeded on aged stroma [74]. Furthermore, young HSCs transplanted to aged niches exhibit impairment in homing and decreased potential for differentiation [75].

Another characteristic of aged HSCs is an altered differentiation potential tending toward higher myeloid/ platelet output and lower lymphoid output. Skewing toward myeloid differentiation is attributed to the microenvironment since transplantation of young HSCs to aged recipients resulted in increased output of myeloid lineages [75]. Transplantation experiments show that granulocyte-macrophage progenitor (GMP) expansion is comparable regardless of donor age, hinting a strong influence of the microenvironment for myeloid lineages [76]. Furthermore, impaired production of pre-B-cells in lethally irradiated old mice transplanted with young BM implies that differentiation of B-cells depends on the BM microenvironment [77]. Similarly, T cell lymphopoiesis in the thymus was also more efficient in a young thymic microenvironment, as evident in aged mice carrying a fetal thymus transplanted into the kidney capsule [78]. Nevertheless, the identification of heterogeneity in the lineage commitment among HSCs still indicates cell-intrinsic, stochastic emergence of lineage-biased clones [79]. The degree by which the aged niche influences lineage commitment remains to be determined.

The change in interactions between the aged niche and HSCs is illustrated by the change in the HSC cytoskeleton. A study using a time-lapse two photon microscopy to visualize aged or young HSPCs engrafting in the BM revealed a change in the interaction between aged HSCs and the niche. Aged HSPCs engrafted distal to the periosteal region of the BM and showed less cellular polarity [80]. A decline in cell polarity is an age-acquired characteristic of HSCs [81]. The reports indicate that aged HSCs occupy different niches from young HSCs; the question remains whether aged niches preferentially repel or cause adhesion of HSCs and directly influence HSC cell polarity.

Molecular mechanisms of age-related changes in niche cells

While the cellular characterization of the aged HSC niche progresses, studies reporting the molecular mechanisms of aging in the niche have been reported sporadically. Telomere lengths in aged MSCs shorten with age, particularly in vitro [82]. Recipient mice with reduced telomerase activity ( $\operatorname{Terc}^{-1-}$ mice) exhibited impaired B lymphopoiesis and increased myelopoiesis, indicating that accumulation of DNA damage through telomerase insufficiency in the microenvironment can accelerate HSC aging [83]. Terc $^{-1-}$ mice displayed a decrease in early mesenchymal progenitor cell populations along with alterations in systemic levels of granulocyte colony stimulating factor (G-CSF) [83]. This study clearly demonstrates that telomerase dysfunction and accumulation of DNA damage within the microenvironment can provoke HSC aging; however, investigation of the vulnerability of various niche cells to aging processes and elucidation of the contribution of these events in physiological and pathological aging is needed.

Changes in adhesion between HSCs and niche cells may also be a mechanism of aging in the hematopoietic system, similar to other stem cell systems. Indeed, expression of various adhesion molecules in HSCs alters with age [84]. Aged HSCs express low levels of integrin $\alpha 4$, integrin $\alpha 5$ and VCAM-1, and high levels of P-selectin and integrin $\alpha 6$ compared to young HSCs [76, 84]. Also, aged HSCs 
functionally exhibit less adhesion to stromal cells in culture [5]. Overexpression of Cdc42, a small Rho GTPase that is involved in adhesion signaling, causes premature aging phenotypes [85]. In the hematopoietic system, HSCs overexpressing Cdc42 showed aging HSC phenotypes with loss of repopulation potential, myeloid skewing, and decreased cell polarity [81]. As small Rho GTPases alter cell adhesive properties in response to cell extrinsic stimulus [84], it is of interest whether changes in adhesive properties of niche cells are also involved in alterations in this pathway.

Age-related changes in niche cells may also be attributed to changes in their metabolic state. Accumulation of reactive oxygen species (ROS), a by-product of mitochondrial respiration, has been demonstrated in aged niche cells in the Drosophila ovary; overexpression of superoxide dismutase (SOD) in cap cells reduces ROS in niche cells and extends GSC life span [51]. Similarly, MSCs obtained from aged human BMs revealed elevated ROS levels along with $p 21$ and p53 expression, indicating cellular senescence in BM MSCs [86]. Furthermore, high oxygen tension has been associated with senescence in cultured human BM MSCs. When cultured in continuous hypoxia, human MSCs exhibited higher self-renewal divisions without an increase in cellular senescence [87]. MSCs cultured in higher oxygen levels exhibited utilization of oxidative phosphorylation compared to those cultured in hypoxia, suggesting that the generation of reactive oxidative species may influence MSC senescence. Further studies are necessary to link age-related metabolic changes in MSCs to their function as a HSC niche.

\section{HSC mobilization and aging of the niche}

The association between age-related changes in niche components that influence HSC mobilization in the BM is especially important in the context of clinical applications. Aged patients have low yields of mobilized HSCs for therapy [88], [89]. However, animal models revealed a contradictory effect in which G-CSF-induced mobilization was increased in aged mice [5]. To clarify these discrepancies, a barcoding technique was used to identify the distribution of individual transplanted HSC clones. Barcoded aged and young transplanted HSCs present a skewed distribution that did not show equilibration even by 11 months after transplantation [90]. Mobilization induced through an one-time administration of G-CSF to mice following either aged or young transplanted HSCs sufficiently equilibrated the skewed distribution of transplanted HSC clones indicating that cell kinetics upon mobilization did not differ between aged and young HSCs. These data suggest that differences in mobilization potential according to age are influenced mainly by the niche in which the
HSCs reside. The study also indicates that specific HSC clones occupy specific niches post-transplantation, indicating that the clonality of HSCs may largely be influenced by specific niche cells at different anatomical sites. Whether the skewed distribution holds for steady-state hematopoiesis without BM transplantation of aged or young $\mathrm{BMs}$ remain to be investigated.

Hematological malignancy and aging of the niche

Leukemic stem cells (LSC) or leukemia initiating cells (LIC), which have the potential to initiate leukemia, mimic HSCs when they undergo self-renewal and remain quiescent [91], [92]. It is, therefore, likely that LSCs may hijack niches normally occupied by HSCs and utilize the niches for leukemic propagation. Indeed, ample evidence suggests that LSCs are influenced by the niche [93]. For example, deletion of the retinoic acid receptor gamma $(\operatorname{RAR} \gamma)$ or the retinoblastoma gene in the BM microenvironment results in a myeloproliferative disorder [94, 95]. Genetic mutations in osteoblast lineage cells cause hematopoietic malignancies, and deletion of the RNase III endonuclease Dicer1 in osteoprogenitors results in myelodysplasia and acute myeloid leukemia (AML) [96, 97]. Constitutive activation of $\beta$-catenin in osteoblasts also induces the emergence of AML [98]. Leukemic cells are also reported to remodel the $\mathrm{BM}$ niche to a leukemia-permissive environment [99]. An inducible Scl-tTA::TRE-BCR/ABL (BA) double-transgenic mouse model for chronic-phase chronic myeloid leukemia (CML) revealed that myeloid cells from these mice stimulated MSCs to differentiate into osteoblasts [99]. These osteoblasts were less supportive of normal HSC activity and favored leukemic myeloid cell development.

The incidence of many hematopoietic malignancies, including myelodysplastic syndrome (MDS) and chronic lymphocytic leukemia (CLL), markedly increase with age [100]. The increase in the incidence of leukemia with age has mainly been attributed to cell-intrinsic alterations to cause mutations transforming hematopoietic cells to LSCs [101]. Nevertheless, the possibility that the emergence and competence of LSCs relies on their residing in the proper microenvironment, especially in the context of age-related changes, has been questioned [93]. For instance, aged BM microenvironments nourish expansion of single dominant clones of transplanted hematopoietic cells, in contrast to young microenvironments that give rise to multiple clones, suggesting that aged microenvironments may support the emergence of leukemic clones [102]. The influence of the aged microenvironment on leukemic cells has been investigated by transplantation of BM cells transfected with an AML-ETO fusion protein into either aged or young recipient mice [103]. The AML-ETO fusion protein is a 
product of a frequent genetic alteration $(\mathrm{t}(8 ; 21))$ that initiates acute myeloid leukemia. Aged mice recipients showed a higher potential to expand AML-ETO transfected cells within the BM, but not in the spleen, suggesting that the local aged BM microenvironment, and not systemic effects of aging, affect leukemic cell expansion. Whether aged microenvironments will foster LSCs after secondary genetic lesions following the development of AML-ETO has not been tested, however.

\section{Future insights}

The utilization of in vivo cell-specific deletion of molecules has recently contributed to the elucidation of functional niches in the BM; however, these systems have not been used to study hematopoiesis in aged mice. The degree by which cell autonomous or cell extrinsic influences from the niche determine the aging of HSCs is still a major question. Research on molecular and genetic mechanisms of cell-intrinsic regulation of $\mathrm{HSCs}$ and identification of novel markers for aged HSCs should enable progress in the study of age-related changes in the BM niche in the future. Irrespective of whether aging in the hematopoietic system occurs through HSC intrinsic or extrinsic processes, the identification of how aging proceeds in the BM niche will reveal essential clues for the treatment of age-related hematopoietic diseases.

Acknowledgments A.N-I is supported by a fellowship from Japan Society for the Promotion of Science (JSPS) and JSPS KAKENHI grant number 26713035. T.S. is supported by the Seventh Framework Programme of the European Union under grant agreement number 306240 (SystemAge) and a Grant-in-Aid from JSPS. The authors apologize to those whose work could not be discussed owing to space limitations.

\section{References}

1. Weissman IL. Stem cells. Cell. 2000;100:157-68.

2. Till JE, McCulloch EA, Siminovitch L. A stochastic model of stem cell proliferation, based on the growth of spleen colonyforming cells. Proc Natl Acad Sci USA. 1964;51:29-36.

3. Beerman I, Bhattacharya D, Zandi S, Sigvardsson M, Weissman IL, Bryder D, et al. Functionally distinct hematopoietic stem cells modulate hematopoietic lineage potential during aging by a mechanism of clonal expansion. Proc Natl Acad Sci USA. 2010;107:5465-70.

4. Morrison SJ, Wandycz AM, Akashi K, Globerson A, Weissman IL. The aging of hematopoietic stem cells. Nat Med. 1996;2:1011-6.

5. Xing Z, Ryan MA, Daria D, Nattamai KJ, Van Zant G, Wang L, et al. Increased hematopoietic stem cell mobilization in aged mice. Blood. 2006;108:2190-7.

6. Chambers SM, Shaw CA, Gatza C, Fisk CJ, Donehower LA, Goodell MA. Aging hematopoietic stem cells decline in function and exhibit epigenetic dysregulation. PLoS Biol. 2007;5:e201.
7. Schofield R. The relationship between the spleen colony-forming cell and the haemopoietic stem cell. Blood Cells. 1978;4:7-25.

8. Zhang J, Niu C, Ye L, Huang H, He X, Tong W-G, et al. Identification of the haematopoietic stem cell niche and control of the niche size. Nature. 2003;425:836-41.

9. Arai F, Hirao A, Ohmura M, Sato H, Matsuoka S, Takubo K, et al. Tie2/Angiopoietin-1 signaling regulates hematopoietic stem cell quiescence in the bone marrow niche. Cell. 2004;118:149-61.

10. Ding L, Saunders TL, Enikolopov G, Morrison SJ. Endothelial and perivascular cells maintain haematopoietic stem cells. Nature. 2012;481:457-62.

11. Butler JM, Nolan DJ, Vertes EL, Varnum-Finney B, Kobayashi H, Hooper AT, et al. Endothelial cells are essential for the selfrenewal and repopulation of Notch-dependent hematopoietic stem cells. Cell Stem Cell. 2010;6:251-64.

12. Sugiyama T, Kohara H, Noda M, Nagasawa T. Maintenance of the hematopoietic stem cell pool by CXCL12-CXCR4 chemokine signaling in bone marrow stromal cell niches. Immunity. 2006;25:977.

13. Méndez-Ferrer S, Michurina VT, Ferraro F, Macarthur BD, Lira $\mathrm{SA}$, et al. Mesenchymal and haematopoietic stem cells form a unique bone marrow niche. Nature. 2010;466:829-34.

14. Katayama Y, Battista M, Kao W-M, Hidalgo A, Peired AJ, Thomas SA, et al. Signals from the sympathetic nervous system regulate hematopoietic stem cell egress from bone marrow. Cell. 2006; $124: 407$.

15. Naveiras O, Nardi V, Wenzel PL, Hauschka PV, Fahey F, Daley GQ. Bone-marrow adipocytes as negative regulators of the haematopoietic microenvironment. Nature. 2009;460:259-63.

16. Yamazaki S, Ema H, Karlsson G, Yamaguchi T, Miyoshi H, Shioda S, et al. Nonmyelinating Schwann cells maintain hematopoietic stem cell hibernation in the bone marrow niche. Cell. 2011;147:1146-58.

17. Chow A, Lucas D, Hidalgo A, Méndez-Ferrer S, Hashimoto D, Scheiermann C, et al. Bone marrow CD169+ macrophages promote the retention of hematopoietic stem and progenitor cells in the mesenchymal stem cell niche. J Exp Med. 2011;208:261-71.

18. Fujisaki J, Wu J, Carlson AL, Silberstein L, Putheti P, Larocca R, et al. In vivo imaging of Treg cells providing immune privilege to the haematopoietic stem-cell niche. Nature. 2011;474:216-9.

19. Kollet O, Dar A, Shivtiel S, Kalinkovich A, Lapid K, Sztainberg $\mathrm{Y}$, et al. Osteoclasts degrade endosteal components and promote mobilization of hematopoietic progenitor cells. Nat Med. 2006;12:657-64.

20. Arai F, Hirao A, Ohmura M, Sato H, Matsuoka S, Takubo K, et al. Tie2/angiopoietin-1 signaling regulates hematopoietic stem cell quiescence in the bone marrow niche. Cell. 2004;118:149-61.

21. Yoshihara H, Arai F, Hosokawa K, Hagiwara T, Takubo K, Nakamura Y, et al. Thrombopoietin/MPL signaling regulates hematopoietic stem cell quiescence and interaction with the osteoblastic niche. Cell Stem Cell. 2007;1:685-97.

22. Nilsson SK, Johnston HM, Whitty GA, Williams B, Webb RJ, Denhardt DT, et al. Osteopontin, a key component of the hematopoietic stem cell niche and regulator of primitive hematopoietic progenitor cells. Blood. 2005;106:1232-9.

23. Nakamura-Ishizu A, Okuno Y, Omatsu Y, Okabe K, Morimoto $\mathrm{J}$, Uede $\mathrm{T}$, et al. Extracellular matrix protein Tenascin-C is required in the bone marrow microenvironment primed for hematopoietic regeneration. Blood. 2012;119(23):5429-37.

24. Hosokawa K, Arai F, Yoshihara H, Iwasaki H, Nakamura Y, Gomei $\mathrm{Y}$, et al. Knockdown of N-cadherin suppresses the long- 
term engraftment of hematopoietic stem cells. Blood. 2010;116: 554-63.

25. Constien R, Forde A, Liliensiek B, Gröne HJ, Nawroth P, Hämmerling G, et al. Characterization of a novel EGFP reporter mouse to monitor Cre recombination as demonstrated by a Tie 2 Cre mouse line. Genesis. 2001;30:36-44.

26. Kisanuki YY, Hammer RE, Miyazaki J, Williams SC, Richardson JA, Yanagisawa M. Tie2-Cre transgenic mice: a new model for endothelial cell-lineage analysis in vivo. Dev Biol. 2001;230:230-42.

27. Alva JA, Zovein AC, Monvoisin A, Murphy T, Salazar A, Harvey NL, et al. VE-Cadherin-Cre-recombinase transgenic mouse: a tool for lineage analysis and gene deletion in endothelial cells. Dev Dyn. 2006;235:759-67.

28. Monvoisin A, Alva JA, Hofmann JJ, Zovein AC, Lane TF, Iruela-Arispe ML. VE-cadherin-CreERT2 transgenic mouse: a model for inducible recombination in the endothelium. Dev Dyn. 2006;235:3413-22.

29. Sun JF, Phung T, Shiojima I, Felske T, Upalakalin JN, Feng D, et al. Microvascular patterning is controlled by fine-tuning the Akt signal. Proc Natl Acad Sci USA. 2005;102:128-33.

30. Sörensen I, Adams RH, Gossler A. DLL1-mediated Notch activation regulates endothelial identity in mouse fetal arteries. Blood. 2009; 113:5680-8.

31. Logan M, Martin JF, Nagy A, Lobe C, Olson EN, Tabin CJ. Expression of Cre recombinase in the developing mouse limb bud driven by a Prxl enhancer. Genesis. 2002;33:77-80.

32. Trumpp A, Depew MJ, Rubenstein JLR, Bishop JM, Martin GR. Cre-mediated gene inactivation demonstrates that FGF8 is required for cell survival and patterning of the first branchial arch. Genes Dev. 1999;13:3136-48.

33. Yeo H, Beck LH, Thompson SR, Farach-Carson MC, McDonald JM, Clemens TL, et al. Conditional disruption of calcineurin B1 in osteoblasts increases bone formation and reduces bone resorption. J Biol Chem. 2007;282:35318-27.

34. Dacquin R, Starbuck M, Schinke T, Karsenty G. Mouse alpha1(I)-collagen promoter is the best known promoter to drive efficient Cre recombinase expression in osteoblast. Dev Dyn. 2002;224:245-51.

35. Liu F, Woitge HW, Braut A, Kronenberg MS, Lichtler AC, Mina M, et al. Expression and activity of osteoblast-targeted Cre recombinase transgenes in murine skeletal tissues. J Dev Biol. 2004;48:645-53.

36. Rodda SJ, McMahon AP. Distinct roles for hedgehog and canonical Wnt signaling in specification, differentiation and maintenance of osteoblast progenitors. Development. 2006;133: $3231-44$

37. Maes C, Kobayashi T, Kronenberg HM. A novel transgenic mouse model to study the osteoblast lineage in vivo. Ann N Y Acad Sci. 2007;1116:149-64.

38. Kalajzic I, Braut A, Guo D, Jiang X, Kronenberg MS, Mina M, et al. Dentin matrix protein 1 expression during osteoblastic differentiation, generation of an osteocyte GFP-transgene. Bone. 2004;35:74-82.

39. Lu Y, Xie Y, Zhang S, Dusevich V, Bonewald LF, Feng JQ. DMP1-targeted Cre expression in odontoblasts and osteocytes. J Dent Res. 2007;86:320-5.

40. Kühn R, Schwenk F, Aguet M, Rajewsky K. Inducible gene targeting in mice. Science. 1995;269:1427-9.

41. Georgiades P, Ogilvy S, Duval H, Licence DR, Charnock-Jones DS, Smith SK, et al. VavCre transgenic mice: a tool for mutagenesis in hematopoietic and endothelial lineages. Genesis. 2002;34:251-6.

42. de Boer J, Williams A, Skavdis G, Harker N, Coles M, Tolaini $\mathrm{M}$, et al. Transgenic mice with hematopoietic and lymphoid specific expression of Cre. Eur J Immunol. 2003;33:314-25.
43. Croker BA, Metcalf D, Robb L, Wei W, Mifsud S, DiRago L, et al. SOCS3 is a critical physiological negative regulator of G-CSF signaling and emergency granulopoiesis. Immunity. 2004;20:153-65.

44. Göthert JR, Gustin SE, Hall MA, Green AR, Göttgens B, Izon $\mathrm{DJ}$, et al. In vivo fate-tracing studies using the Scl stem cell enhancer: embryonic hematopoietic stem cells significantly contribute to adult hematopoiesis. Blood. 2005;105:2724-32.

45. Barker JE. $S l / S l^{d}$ hematopoietic progenitors are deficient in situ. Exp Hematol. 1994;22:174-7.

46. Tokoyoda K, Egawa T, Sugiyama T, Choi B-I, Nagasawa T. Cellular niches controlling B lymphocyte behavior within bone marrow during development. Immunity. 2004;20:707-18.

47. Nagasawa T, Omatsu Y, Sugiyama T. Control of hematopoietic stem cells by the bone marrow stromal niche: the role of reticular cells. Trends Immunol. 2011;32(7):315-20.

48. Ding L, Morrison SJ. Haematopoietic stem cells and early lymphoid progenitors occupy distinct bone marrow niches. Nature. 2013;495(7440):231-5.

49. Greenbaum A, Hsu Y-MS, Day RB, Schuettpelz LG, Christopher MJ, Borgerding JN, et al. CXCL12 in early mesenchymal progenitors is required for haematopoietic stem-cell maintenance. Nature. 2013;495:227-30.

50. Decotto E, Spradling AC. The Drosophila ovarian and testis stem cell niches: similar somatic stem cells and signals. Dev Cell. 2005;9:501-10.

51. Pan L, Chen S, Weng C, Call G, Zhu D, Tang H, et al. Stem cell aging is controlled both intrinsically and extrinsically in the Drosophila ovary. Cell Stem Cell. 2007;1:458-69.

52. Boyle M, Wong C, Rocha M, Jones DL. Decline in self-renewal factors contributes to aging of the stem cell niche in the Drosophila testis. Cell Stem Cell. 2007;1:470-8.

53. de Cuevas M, Matunis EL. The stem cell niche: lessons from the Drosophila testis. Development. 2011;138:2861-9.

54. Toledano H, D'Alterio C, Czech B, Levine E, Jones DL. The let7-Imp axis regulates ageing of the Drosophila testis stem-cell niche. Nature. 2012;485:605-10.

55. Boyle M, Wong C, Rocha M, Jones DL. Decline in self-renewal factors contributes to aging of the stem cell niche in the Drosophila testis. Cell Stem Cell. 2007;1:470-8.

56. Doetsch F. A niche for adult neural stem cells. Curr Opin Genet Dev. 2003; 13:543-50

57. Ramírez-Castillejo C, Sánchez-Sánchez F, Andreu-Agulló C, Ferrón SR, Aroca-Aguilar JD, Sánchez P, et al. Pigment epithelium-derived factor is a niche signal for neural stem cell renewal. Nat Neurosci. 2006;9:331-9.

58. Sii-Felice K, Etienne O, Hoffschir F, Mathieu C, Riou L, Barroca $\mathrm{V}$, et al. Fanconi DNA repair pathway is required for survival and long-term maintenance of neural progenitors. EMBO J. 2008;27:770-81.

59. Enwere E, Shingo T, Gregg C, Fujikawa H, Ohta S, Weiss S. Aging results in reduced epidermal growth factor receptor signaling, diminished olfactory neurogenesis, and deficits in fine olfactory discrimination. J Neurosci. 2004;24:8354-65.

60. Pineda JR, Daynac M, Chicheportiche A, Cebrian-Silla A, Sii K, Felice, Garcia-Verdugo JM, et al. Vascular-derived TGF- $\beta$ increases in the stem cell niche and perturbs neurogenesis during aging and following irradiation in the adult mouse brain. EMBO Mol Med. 2013;5:548-62.

61. I.M. Conboy, M.J. Conboy, G.M. Smythe, T.A. Rando, Notchmediated restoration of regenerative potential to aged muscle., Science (New York, N.Y.). 302 (2003) 1575-7.

62. Carlson ME, Conboy MJ, Hsu M, Barchas L, Jeong J, Agrawal A, et al. Relative roles of TGF-betal and Wnt in the systemic regulation and aging of satellite cell responses. Aging Cell. 2009;8:676-89. 
63. Conboy MJ, Conboy IM, Rando TA, Service N, Alto P. Heterochromatic parabiosis: historical perspective and methodological considerations for studies of aging and longevity. Aging Cell. 2013;12(3):525-30.

64. Conboy IM, Conboy MJ, Wagers AJ, Girma ER, Weissman IL, Rando TA. Rejuvenation of aged progenitor cells by exposure to a young systemic environment. Nature. 2005;433:760-4.

65. Carlson ME, Conboy IM. Loss of stem cell regenerative capacity within aged niches. Aging Cell. 2007;6:371-82.

66. Villeda SA, Luo J, Mosher KI, Zou B, Britschgi M, Bieri G, et al. The ageing systemic milieu negatively regulates neurogenesis and cognitive function. Nature. 2011;477:90-4.

67. Ruckh JM, Zhao J-W, Shadrach JL, van Wijngaarden P, Rao $\mathrm{TN}$, Wagers AJ, et al. Rejuvenation of regeneration in the aging central nervous system. Cell Stem Cell. 2012;10:96-103.

68. Wagner W, Horn P, Bork S, Ho AD. Aging of hematopoietic stem cells is regulated by the stem cell niche. Exp Gerontol. 2008;43:974-80.

69. Tokalov SV, Grüner S, Schindler S, Wolf G, Baumann M, Abolmaali N. Age-related changes in the frequency of mesenchymal stem cells in the bone marrow of rats. Stem Cells Dev. 2007;16:439-46.

70. Bellantuono I, Aldahmash A, Kassem M. Aging of marrow stromal (skeletal) stem cells and their contribution to age-related bone loss. Biochim Biophys Acta. 2009;1792:364-70.

71. Stenderup K. Aging is associated with decreased maximal life span and accelerated senescence of bone marrow stromal cells. Bone. 2003;33:919-26.

72. Yvan-Charvet L, Pagler T, Gautier EL, Avagyan S, Siry RL, Han S, et al. ATP-binding cassette transporters and HDL suppress hematopoietic stem cell proliferation. Science. 2010;328:1689-93.

73. Omatsu Y, Seike M, Sugiyama T, Kume T, Nagasawa T. Foxc1 is a critical regulator of haematopoietic stem/progenitor cell niche formation. Nature. 2014;508(7497):536-40.

74. Hotta T, Hirabayashi N, Utsumi M, Murate T, Yamada H. Agerelated changes in the function of hemopoietic stroma in mice. Exp Hematol. 1980;8:933-6.

75. Liang Y, Van Zant G, Szilvassy SJ. Effects of aging on the homing and engraftment of murine hematopoietic stem and progenitor cells. Blood. 2005;106:1479-87.

76. Rossi DJ, Bryder D, Zahn JM, Ahlenius H, Sonu R, Wagers AJ, et al. Cell intrinsic alterations underlie hematopoietic stem cell aging. Proc Natl Acad Sci USA. 2005;102:9194-9.

77. Li F, Jin F, Freitas A, Szabo P, Weksler ME. Impaired regeneration of the peripheral $\mathrm{B}$ cell repertoire from bone marrow following lymphopenia in old mice. Eur J Immunol. 2001;31: $500-5$.

78. Zhu X, Gui J, Dohkan J, Cheng L, Barnes PF, Su D-M. Lymphohematopoietic progenitors do not have a synchronized defect with age-related thymic involution. Aging Cell. 2007;6:663-72.

79. Miller PH, Knapp DJHF, Eaves CJ. Heterogeneity in hematopoietic stem cell populations: implications for transplantation. Curr Opin Hematol. 2013;20:257-64.

80. Köhler A, Schmithorst V, Filippi M-D, Ryan MA, Daria D, Gunzer M, et al. Altered cellular dynamics and endosteal location of aged early hematopoietic progenitor cells revealed by time-lapse intravital imaging in long bones. Blood. 2009;114: 290-8.

81. Florian MC, Dörr K, Niebel A, Daria D, Schrezenmeier H, Rojewski M, et al. Cdc42 activity regulates hematopoietic stem cell aging and rejuvenation. Cell Stem Cell. 2012;10:520-30.

82. Baxter MA, Wynn RF, Jowitt SN, Wraith JE, Fairbairn LJ, Bellantuono I. Study of telomere length reveals rapid aging of human marrow stromal cells following in vitro expansion. Stem Cells. 2004;22:675-82.
83. Ju Z, Jiang H, Jaworski M, Rathinam C, Gompf A, Klein C, et al. Telomere dysfunction induces environmental alterations limiting hematopoietic stem cell function and engraftment. Nat Med. 2007;13:742-7.

84. Geiger H, Koehler A, Gunzer M. Stem cells, aging, niche, adhesion and Cdc42: a model for changes in cell-cell interactions and hematopoietic stem cell aging. Cell Cycle. 2007;6: 884-7.

85. Wang L, Yang L, Debidda M, Witte D, Zheng Y. Cdc42 GTPase-activating protein deficiency promotes genomic instability and premature aging-like phenotypes. Proc Natl Acad Sci USA. 2007;104:1248-53.

86. Stolzing A, Jones E, McGonagle D, Scutt A. Age-related changes in human bone marrow-derived mesenchymal stem cells: consequences for cell therapies. Mech Ageing Dev. 2008;129:163-73.

87. Pattappa G, Thorpe SD, Jegard NC, Heywood HK, de Bruijn JD, Lee DA. Continuous and uninterrupted oxygen tension influences the colony formation and oxidative metabolism of human mesenchymal stem cells. Tissue Eng Part C Methods. 2013;19: 68-79.

88. Pozotrigo M, Adel N, Landau H, Lesokhin A, Lendvai N, Chung DJ, et al. Factors impacting stem cell mobilization failure rate and efficiency in multiple myeloma in the era of novel therapies: experience at Memorial Sloan Kettering Cancer Center. Bone Marrow Transpl. 2013;48:1033-9.

89. Morris CL, Siegel E, Barlogie B, Cottler-Fox M, Lin P, Fassas A, et al. Mobilization of CD34+ cells in elderly patients $(>/$ $=70$ years) with multiple myeloma: influence of age, prior therapy, platelet count and mobilization regimen. Br J Haematol. 2003;120:413-23.

90. Verovskaya E, Broekhuis MJC, Zwart E, Weersing E, Ritsema $\mathrm{M}$, Bosman LJ, et al. Asymmetry in skeletal distribution of mouse hematopoietic stem cell clones and their equilibration by mobilizing cytokines. J Exp Med. 2014;211:487-97.

91. Huntly BJP, Gilliland DG. Leukaemia stem cells and the evolution of cancer-stem-cell research. Nat Rev Cancer. 2005;5:311-21.

92. Lapidot T, Sirard C, Vormoor J, Murdoch B, Hoang T, CaceresCortes $\mathrm{J}$, et al. A cell initiating human acute myeloid leukaemia after transplantation into SCID mice. Nature. 1994;367:645-8.

93. Lane SW, Scadden DT, Gilliland DG. The leukemic stem cell niche: current concepts and therapeutic opportunities. Blood. 2009;114:1150-7.

94. Walkley CR, Olsen GH, Dworkin S, Fabb SA, Swann J, McArthur GA, et al. A microenvironment-induced myeloproliferative syndrome caused by retinoic acid receptor gamma deficiency. Cell. 2007;129:1097-110.

95. Walkley CR, Shea JM, Sims NA, Purton LE, Orkin SH. Rb regulates interactions between hematopoietic stem cells and their bone marrow microenvironment. Cell. 2007;129:1081-95.

96. Raaijmakers MHGP, Mukherjee S, Guo S, Zhang S, Kobayashi $\mathrm{T}$, Schoonmaker JA, et al. Bone progenitor dysfunction induces myelodysplasia and secondary leukaemia. Nature. 2010;464: $852-7$.

97. Raaijmakers MH. Myelodysplastic syndromes: revisiting the role of the bone marrow microenvironment in disease pathogenesis. Int J Hematol. 2012;95:17-25.

98. Kode A, Manavalan JS, Mosialou I, Bhagat G, Rathinam CV, Luo $N$, et al. Leukaemogenesis induced by an activating $\beta$ catenin mutation in osteoblasts. Nature. 2014;506:240-4.

99. Schepers K, Pietras EM, Reynaud D, Flach J, Binnewies M, Garg T, et al. Myeloproliferative neoplasia remodels the endosteal bone marrow niche into a self-reinforcing leukemic niche. Cell Stem Cell. 2013;13:285-99. 
100. Hamaker ME, Prins MC, Stauder R. The relevance of a geriatric assessment for elderly patients with a haematological malignancy-a systematic review. Leuk Res. 2014;38:275-83.

101. Rossi DJ, Bryder D, Seita J, Nussenzweig A, Hoeijmakers J, Weissman IL. Deficiencies in DNA damage repair limit the function of haematopoietic stem cells with age. Nature. $2007 ; 447: 725-9$.
102. Vas V, Senger K, Dörr K, Niebel A, Geiger H. Aging of the microenvironment influences clonality in hematopoiesis. PLoS ONE. 2012;7:e42080.

103. Vas V, Wandhoff C, Dörr K, Niebel A, Geiger H. Contribution of an aged microenvironment to aging-associated myeloproliferative disease. PLoS ONE. 2012;7:e31523. 